\title{
Prevalence, isolation and antibiogram of mastitis causing microbes in achai cows
}

\begin{abstract}
Mastitis is still the most important and widespread zoonotic production disease in milking herds in all species of farm animals, despite several decades of research and remedial efforts. It has a long range of damaging effects on productive performance of animals in almost all parts of the inhabited regions of the world. The current study was performed at Livestock Research and Development Station, Surezai and Dir lower. The dual aims of the current study were to evaluate the incidence rate of mastitis in Achai cattle and to study the antibiogram pattern of mastitis causing microbes after isolation from the positive samples. For this purpose, Achai cows in lactating stage were divided in two groups viz. $\mathrm{A}(\mathrm{n}=10)$ and $(\mathrm{B} \mathrm{n}=10)$ based on the stage of lactation. During this study, 1,945 samples collected from Achai cows were screened for clinical and subclinical mastitis through Surf Field Mastitis Test (SFMT). Out of total, only 09 samples were found positive for sub-clinical mastitis and no sample for clinical mastitis. The results revealed that the incidence of mastitis in Achai cattle was very rare $(0.46 \%)$. The culture incubation of the positive samples revealed thatmixed growth of E. coli and ProteusSpp., Klebsiella spp. and ProteusSpp. were isolated. The results also revealed that Gentamycin, Enrofloxacin and Norfloxacin were the most potent drug for the treatment of Mastitis, followed by Ciprofloxacin in that order. The results further suggested that the incidence of sub-clinical Mastitis could be decreased through adopting hygiene measures and good managemental practices.
\end{abstract}

Volume 7 Issue 2 - 2018

\author{
Muhammad Nauman-ul-Islam,' Muhammad \\ Sohail,' Hayazuddin,2 Imtiaz Ali Shah,' \\ Rafiullah, ${ }^{2}$ Khisrao Kalim, ' Anwer Ali Turi, ${ }^{2}$ \\ Inamullah wazir ${ }^{2}$, Zubina Hameed ${ }^{2}$ \\ 'Livestock Research and Development Station, Pakistan \\ ${ }^{2}$ Livestock and Dairy Development Department (Research \\ Wing), Pakistan
}

Correspondence: Muhammad Nauman-ul-Islam, Livestock Research and Development Station, Surezai, Pakistan, Tel 03349042456,Email youngdr66@gmail.com

Received: November 22, 2017 | Published: March 16, 2018

Keywords: Achai Cattle, SFMT, Sub-clinical Mastitis

\section{Introduction}

Mastitis is still the most important and widespread zoonotic production disease in milking herds in all species of farm animals, despite several decades of research and remedial efforts. It has a long range of damaging effects on productive performance of animals. ${ }^{1}$ In mastitis, the udder becomes inflamed as leukocytes are released into the mammary gland in response to invasion of the teat canal, usually by microbes. These bacteria multiply and produce toxins that cause injury to milk secreting tissue and various ducts throughout the mammary gland. High leukocytes or somatic cells results in a reduction in milk production and change milk composition. These changes in response adversely affect quality and quantity of dairy products. ${ }^{2}$ The relationship of mastitis with milk yield and milk composition has received significant research consideration because of incredible economic implications. Mastitis decreases milk yield and alters milk composition. The extent of reduced milk yield and alterations in milk composition is influenced by severity of the inflammatory response, which in turn is influenced by the mastitis pathogen causing the illness. ${ }^{2}$ Milk drawn from an infected cow can transmit pathogenic bacteria to humans through food chain which is dangerous to the public health. Earlier, it has been revealed that milk can transmit Tuberculosis, brucellosis, diphtheria, scarlet fever and $\mathrm{Q}$ fever to humans. However, these diseases can be controlled by a pasteurization technique, but a variety of bacteria still contribute to illness and diseases outbreak. ${ }^{3}$ It has been recognized as universal problem which is characterized by physical, chemical and microbiological changes in milk while pathological changes in parenchyma cells of the udder. Mastitis is of two forms i.e., clinical and sub-clinical. The prevalence of sub-clinical form is 15-40 times more than clinical form and is responsible for high economic losses. In India and Pakistan prevalence of sub-clinical Mastitis is $17-93 \%$ in cows and $4-48 \%$ in buffalo's respectively. ${ }^{4}$

The risk for transmission of zoonotic diseases like tuberculosis, brucellosis, leptospirosis and streptococcal sore throat to human being is attached with the mastitis. ${ }^{5}$ Microbial infection is amongst the most common causes of mastitis. The development of antibiotic resistance among bacteria that affects animal health is of growing concern in veterinary medicine. Antibiotic resistant bacteria in animals have also become a potential health risk for humans, as they are able to cause direct or indirect transmission of the infection. Therefore, establishing an Antibiogram of pathogens is very important from the clinical and economic points of view. The susceptibility pattern of these microbes to the antibacterial drugs in use is constantly changing and susceptibility of the causing organisms is necessary for the success treatment.

\section{Objectives}

The dual objectives of this study were

i. To investigate the prevalence of Mastitis in Achai cows at LR and DS, Surezai and the commonly occurring microbial organisms responsible for mastitis in Achai cows.

ii. To study the susceptibility pattern of the isolates to various antibacterial drugs. 


\section{Material and methods}

\section{Animal grouping}

The cows $(n=20)$ were divided into two groups (A and B). Group $\mathrm{A}(n=10)$ comprised of fresh lactating Achai cows having a lactation history of up to three months. Group B $(n=10)$ comprised of Achai cows which have a lactation history of more than three months. All animals were maintained under the same routine feeding and management conditions of the farm. The routine feeding consisted of green fodder and grazing, wheat straw with concentrate ration according to the dry matter requirements per body weight of the animals. Vaccination \& deforming was carried out as per schedule. Daily animal milk yield was recorded for each animal.

\section{Sample collection and screening}

The milk samples were collected from Achai cows at LR and DS Surezai \& Dir lower in aseptic conditions and not recently medicated with antibiotics and were screened for Mastitis through Surf Field Mastitis Test (SFMT) according to the protocols of Muhammad et al. ${ }^{6}$

\section{In vitro antibiogram of isolates}

All the positive milk samples were sent to Center of Microbiology and Bacteriology, Veterinary Research Institute, Peshawar. Positive samples were inoculated on Tryptose and Mac Conkey's agar plates as well as on blood agar for microbial isolation. The inoculated plates were incubated at $37^{\circ} \mathrm{C}$ for $24-48$ hours. The isolated microbes were identified on the basis of cultural, morphological characteristic and biochemical reactions. ${ }^{1}$ All the isolated microbes were tested in-vitro for their sensitivity to 17 different antibacterial drugs i.e., Enrofloxacin $(15 \mu \mathrm{g})$, Gentamicin $(10 \mu \mathrm{g})$, Norfloxacin $(10 \mu \mathrm{g})$, Ciprofloxacin $(10 \mu \mathrm{g})$, Streptomycin $(10 \mu \mathrm{g})$, Kanamycin $(30 \mu \mathrm{g})$, Chloramphenicol $(30 \mu \mathrm{g})$, Oxytetracycline $(30 \mu \mathrm{g})$, Flumequine $(10 \mu \mathrm{g})$,Amoxicillin $(10 \mu \mathrm{g})$, Cephradin $(10 \mu \mathrm{g})$, Ampicillin $(10 \mu \mathrm{g})$, Cloxacillin $(5 \mu \mathrm{g})$, Neomycin $(10 \mu \mathrm{g})$, Lincomycin $(10 \mu \mathrm{g})$ and Penicillin (10 i.u.).

\section{Results and discussion}

A total of 1945 samples were collected from the animals selected for research trail and screened for subclinical mastitis through Surf Field Mastitis Test (SFMT) according to the protocols of Muhammad et al. ${ }^{6}$ Only nine (09) samples were found positive which were submitted to Center of Microbiology and Bacteriology, Veterinary Research Institute, Peshawar for the culture isolation and antibiogram studies. The results revealed that the incidence of mastitis in Achai cattle was very rare $(0.46 \%)$. The culture incubation of the positive samples revealed that Mixed growth of E. coli and ProteusSp. and Klebsiella spp. and ProteusSp were isolated (Table 1). The antibiogram of the isolates from the positive samples revealed that the isolated $E$. coli and Proteus $S p$. were most susceptible to Gentamicin, Norfloxacin followed by Ciprofloxacin respectively and showed resistance to the rest of the antibiotics used. Klebsiella $s p$. were most susceptible to Ciprofloxacin, Norfloxacin, followed by Gentamicin and Kanamycin respectively and showed resistance to the rest of the antibiotics used. ProteusSp. were most susceptible to Ciprofloxacin, Norfloxacin, followed by Enrofloxacin and Norfloxacin \& Kanamycin respectively and showed resistance to the rest of the antibiotics used (Table 1).

Table I Isolates and Antibiogram of Mastitis causing microbes in Achai cattle

\begin{tabular}{|c|c|c|c|}
\hline $\begin{array}{l}\text { Sample } \\
\text { No. }\end{array}$ & Isolates & Antibiogram & \\
\hline \multirow[t]{6}{*}{ I } & $\begin{array}{l}\text { Mixed growth of } E \text {. } \\
\text { coli and Proteus Spp. }\end{array}$ & Resistance to Antibiotic(s) & Antibiotic Susceptibility \\
\hline & & Ampicillin, Gentamicin, Kanamycin, & \\
\hline & & Lincomycin, Oxytetracycline, Amoxicillin, & \\
\hline & & & Norfloxacin $(++)$ \\
\hline & & Erythromycin, & \\
\hline & & & Ciprofloxacin $(++)$ \\
\hline \multirow[t]{4}{*}{2} & Klebsiella spp. & Chloramphenicol,Amoxicillin, & Gentamicin $(++)$ \\
\hline & & Doxycycline, Erythromycin, & Enrofloxacin $(+)$ \\
\hline & & Kanamycin, Lincomycin & Norfloxacin $(++)$ \\
\hline & & & Ciprofloxacin $(+++)$ \\
\hline \multirow[t]{3}{*}{3} & Klebsiella spp. & Chloramphenicol,Amoxicillin, & Gentamicin $(+++)$ \\
\hline & & Doxycycline, Erythromycin, & Norfloxacin $(++)$ \\
\hline & & $\begin{array}{l}\text { Kanamycin, Lincomycin, Enrofloxacin, } \\
\text { Oxytetracycline, Sulphamethoxazone }\end{array}$ & Ciprofloxacin (++) \\
\hline \multirow[t]{3}{*}{4} & Proteus Spp. & Chloramphenicol,Amoxicillin, & Gentamicin $(++)$ \\
\hline & & Doxycycline, Erythromycin, & Enrofloxacin $(++)$ \\
\hline & & $\begin{array}{l}\text { Kanamycin, Lincomycin, } \\
\text { Sulphamethoxazone }\end{array}$ & Norfloxacin $(+++)$ \\
\hline
\end{tabular}


Table continued

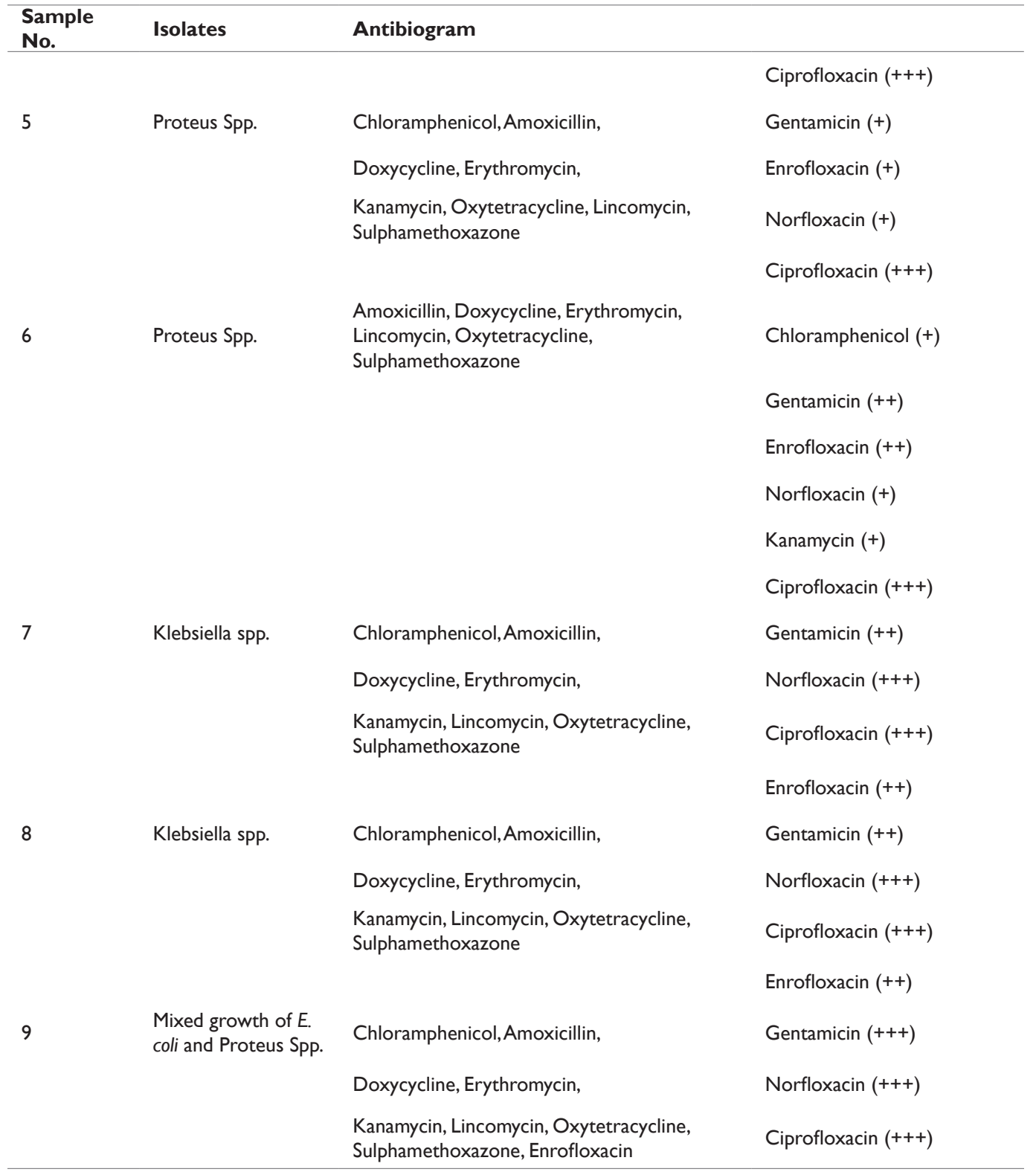

\section{Conclusion}

The rare incidence of mastitis revealed by the current study could be attributed to the good managemental practices and measures to acquire general hygiene on regular basis in milking animals. Our results are in accord with the findings of Herlin et al. ${ }^{7}$ and Hadely et al. ${ }^{8}$ who in their independent studies concluded that incidence of Mastitis infection in lactating cattle could be reduced through maintaining clean surfaces and environments which in turn sustain the defense system of the animal to perform well even in the presence of the pathogens in the environments other than their native. Our results are in conformity with the findings of Reneau et al. ${ }^{9}$ and Ruud et al. ${ }^{10}$ who found the same negligible incidence of sub-clinical Mastitis in lactating cattle through SFMT technique. Our findings are also in line with the study of Barkema et al. ${ }^{11}$ who concluded that lower SSC values are observed generally in herds where hygienic practices were observed and vice versa. Our findings are also supported by the study conducted by ${ }^{12-14}$ who suggested the provision of clean, dry farm premises and concrete flooring which in turn, were found helpful in ensuring the risk free environment for the animals. Achai is yet a significant cattle breed of northern areas of Pakistan which has not been studied extensively for type traits and performance traits. The question that whether Achai cattle do possess some heritable candidate genes for resistance against Mastitis infection is yet to be answered.

\section{Acknowledgement}

None.

\section{Conflict of interest}

None.

\section{References}

1. Seegers H, Fourichon C, Beaudeau F. Production effects related 
to mastitis and mastitis economics in dairy cattle herds. Veterinary Research. 2003;34:475-491.

2. Oliver SP, Calvinho LF. Influence of inflammation on mammary gland metabolism and milk composition. J Animal Sci. 1995;73(2):18-33.

3. Mahantesh MK, Basappa BK. Prevalence and Antimicrobial Susceptibility of Bacteria Isolated From Bovine Mastitis. $P G A d v$ App Sci Res. 2011;2(6):229-235.

4. Allore HG. A review of the incidence of the mastitis in buffaloes and cows. Pak Vet J. 1993;13:1-7.

5. Radostitis OMDC, W Hinchiff, JA Handerson, et al.Veterinary Medicine. $10^{\text {th }}$ edn. London: MB Saunders Company; 2006.

6. Muhammad G, M Athar, A Shakoor, et al. Surf field mastitis test: An expensive new tool for evaluation of wholesomeness of fresh milk. Pakistan J Food Sci. 1995;5(3-4):91-93.

7. Herlin AH. Comparison of lying area surfaces for dairy cows by preference, hygiene and lying down behaviour. Swed J Agric Res. 1997;27:189-196.
8. Hadley GL, Wolf CA, Harsh SB. Dairy cattle culling patterns, explanations, and implications. J Dairy Sci. 2006;89(6):2286-2296.

9. Ruegg PL.The Role of Hygiene in Efficient Milking. WCDS Advances in Dairy Technology. 2006;18:285-293.

10. Ruud LE, Bøe KE, Osterås O.Associations of soft flooring materials in free stalls with milk yield, clinical mastitis, teat lesions, and removal of dairy cows. J Dai Sci. 2010;93(4):1578-1586.

11. Barkema HW, Schukken YH, Lam TJ, et al. Management practices associated with the incidence rate of clinical mastitis. J Dairy Sci. 1999;82(8):1643-1654.

12. Sharif A, Umer M, Muhammad G. Mastitis control in dairy production. J Agri Soc Sci. 2009;5(3):102-105.

13. Oliver SP, Mitchell BA. Prevalence of mastitis pathogens in herds participating in a mastitis control program. J Dairy Sci. 1984;67(10):2436-2440.

14. Schalm OW, D Gray. The White Side test for detection of mastitic milk. Calif Vet. 1954;7:27. 